\title{
The Revolving Door Flap: Revisiting an Elegant but Forgotten Flap for Ear Defect Reconstruction
}

\author{
Anupam Golash'^• Sudipta Bera ${ }^{1} \quad$ Aditya V. Kanoi \\ ${ }^{1}$ Department of Plastic Surgery, Calcutta Medical Research \\ Institute, Kolkata, West Bengal, India \\ ${ }^{2}$ Department of Reconstructive Surgery, Narayana Superspeciality \\ Hospital, Howrah, West Bengal, India \\ ${ }^{3}$ Calcutta Medical College, Kolkata, West Bengal, India \\ Indian J Plast Surg 2020;53:64-70
}

\author{
Abhijit Golash ${ }^{3}$
}

\begin{abstract}
Background The revolving door flap, although well described in the literature, is not widely used in general plastic surgery practice. The flap has been used for anterior auricular and conchal defects and is considered elegant for its unique flap design and peculiarity of flap harvest. However, due to its use for a very specific purpose and unique flap harvest technique that may be difficult to grasp, the flap is not very popular in reconstructive practice.

Objectives This study aims to evaluate the understanding and learning curve of the revolving door flap, assess surgical outcome, and reemphasize its utility and elegance in reconstruction of ear defects.

Methodology This is a case series of nine surgeries performed between January 2014 and 2018. Three cases were performed by the senior author and six cases by two junior authors. Patients were observed for complications and aesthetic outcomes. Results The mean dimension of the flaps was $27.22 \mathrm{~mm} \times 22.78 \mathrm{~mm}$. The mean operative time was 56.56 minutes (standard deviation 22.50, standard error of the mean 7.5). Flap congestion was noted in three cases postoperatively which resolved completely by the second week. Major "pinning" of the ear was noted in four cases.

Keywords

- ear reconstruction

- conchal defect

- revolving door flap

- subcutaneous pedicle

Conclusion Though infrequently performed, the revolving door flap has an easy learning curve once the proper harvest technique and flap movement has been grasped. The flap harvest is convenient, safe, and yields predictable results. Not only is total or partial flap loss extremely rare, the flap is sensate, color match is good, auricular contour is maintained, and the donor site can be closed primarily and remains well hidden.
\end{abstract}

\section{Introduction}

The revolving door (RD) flap or subcutaneous pedicle postauricular island flap is not widely used in general plastic surgery practice $^{1}$ but well described in literature. The flap was first described by Masson in $1971^{2}$ and has been used for various anterior auricular and conchal defects resulting from the excision of malignant tumors. The utility of this flap is well established by the earlier authors and reported incidence of total flap loss is extremely rare. The flap is considered elegant for its unique flap design and peculiarity involved in the harvest technique. ${ }^{3}$ Despite the flap's reliability and elegant harvest, it remains unsung, chiefly because of a lack of awareness.

\section{The Revolving Door Concept}

The earlier authors described the flap harvest technique using the RD, trap door, ${ }^{4}$ pull through, ${ }^{5}$ button hole, ${ }^{6}$ or flip flop $^{7}$ concept, but the three-dimensional harvest technique is difficult to understand without graphical representation. As per the RD concept, the flap revolves from postauricular to preauricular surface on a vertical axis of neurovascular ${ }^{8}$
DOI https://doi.org/

10.1055/s-0040-1709531

ISSN 0970-0358.
License terms

() (1) $\Theta \circledast$ 
subcutaneous pedicle like "wings" of the RD moving on its "shaft" (-Fig. 1a). After undermining the anterior and posterior wings of the flap, the flap hangs on the central shaft of soft tissue attached to the retroauricular groove ( $\mathbf{- F i g . ~} \mathbf{1 b}$ ). The anterior and posterior wings of the elevated flap act as individual wings of the RD and rotate on the central unelevated shaft attached to the retroauricular groove. The shaft acts as subcutaneous soft tissue pedicle of the flap and supplies vascularity from the arterial arcade formed by branches of the posterior auricular and superficial temporal artery in the retroauricular groove. ${ }^{9}$ The subcutaneous tissue in the groove allows a wide range of mobility to the wings. After revolving on its shaft, the anterior and posterior wings of the flap are delivered to the preauricular surface from postauricular surface, through a slit created in the cartilage lying at the bed of the preauricular surface defect. Thus, the wings of the flap are pulled through the cartilage slit in a "button-hole" manner ( - Fig. 2c). Once the wings have been delivered to the preauricular side, the postauricular and mastoid wings are inset into the anterior and posterior margins of the defect respectively. The flap remains attached at the retroauricular groove via the shaft of subcutaneous pedicle ( - Fig. 2 d). Following flap transfer and inset, a new defect (donor defect) is created over the postauricular surface that resembles a standard postauricular full thickness skin graft (FTSG) defect and is closed similarly.

\section{Aims and Objectives}

Understanding of the flap design, harvest, and transfer is crucial for a successful reconstruction. Once well understood, the flap is very easy and safe to raise because of the easy learning curve.
This study aims to assess the understanding and learning curve of the RD flap by evaluating the surgical outcomes using this flap when performed by either the senior author or the junior authors under observation. We also seek to reemphasize its utility and elegance in reconstruction of ear defects.

\section{Methodology}

All the procedures were performed between January 2014 and 2018. Nine cases were included in this study. Three cases were performed by the senior author (A.G.) with the junior authors observing the procedure. The rest six cases were performed by two junior authors under supervision for the first time and subsequently independently.

Eight patients, who attended the plastic surgery outpatient department with suspected malignant lesion of anterior aspect of pinna, were included in this study. A wedge biopsy was performed to confirm malignancy. In one case the flap was done to resurface exposed cartilage after removal of pigmented nevus. All the cases were done under local anesthesia as a daycare procedure. Written informed consent was taken from the patients before each surgery as per the standard ethical guideline.

\section{Surgery}

\section{Excision of Lesion}

The malignant lesions were excised with a 5-mm clear margin and confirmed with a frozen section biopsy. The resultant defect produced a composite loss of anterior auricular skin and cartilage ( - Fig. 2a). In one case of exposed cartilage only, a 3-mm strip of cartilage was also removed to allow flap passage into the defect.
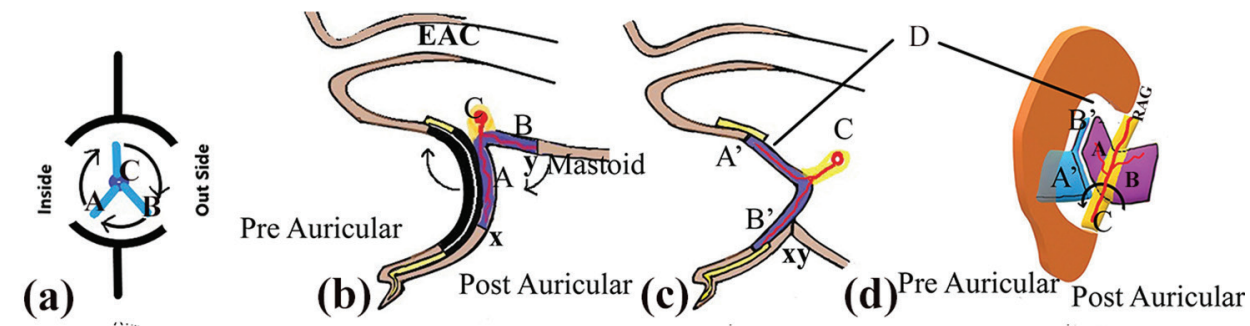

Fig. 1 The Revolving door concept. (a) Revolving door wings (A, B) move on the central shaft (C). (b, c) Schematic axial view of flap harvest and inset. (d) 3D schematic representation. A, retroauricular wing; B, mastoid wing; A', B', repositioned retroauricular and mastoid wing, respectively; C, central shaft of the subcutaneous pedicle and postauricular artery; D, cartilage defect; EAC, external auditory canal; RAG, retroauricular groove; $x, y$, anterior and posterior margin of flap harvest. The black shaded area represents the defect to be reconstructed.

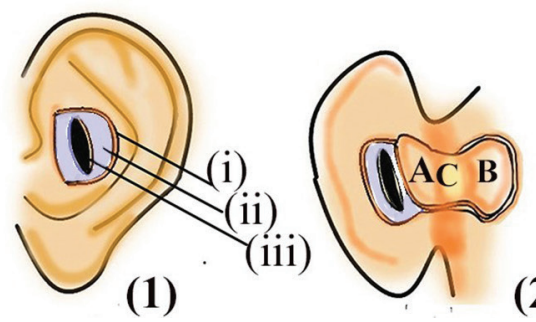

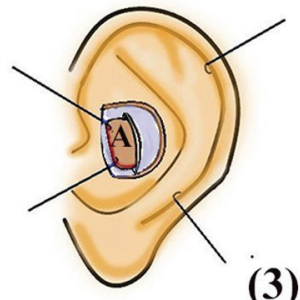

(3)

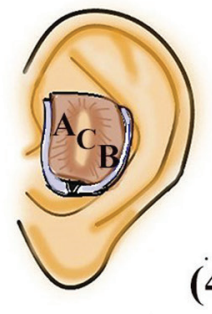

(4)

Fig. 2 Transfer of RD flap through defect. (1) Excision of lesion resulting in composite defect of anterior skin and cartilage-(i) defect margin, (ii) exposed cartilage, (iii) cartilage defect; (2) Raising of the anterior wing of RD flap (A) exposes the cartilage with defect, (3) anterior wing (A) being delivered from posterior to anterior surface through the cartilage defect (4) anterior (A) and posterior (B) wings have been delivered into defect and are ready for inset. C, pedicle. RD, revolving door. 


\section{Flap Harvest}

The defect was marked on the posterior aspect of the pinna using a template. The defect template or pattern was positioned such that the anterior two-thirds of the flap requirement was placed on the postauricular surface (anterior wing) and the remaining one-third over the mastoid (posterior wing) (-Figs. 1b and $\mathbf{2 b}$ ). The flap was designed 15 to $25 \%$ larger than the defect dimensions to aid in transfer and inset. The intervening shaft of subcutaneous tissue in the auriculomastoid groove was preserved with skin only incision to complete the flap margin all around.

\section{Flap Transfer and Inset}

The flap wings were revolved on its vertical axis like an $\mathrm{RD}$. The wings were delivered to the anterior auricular surface of pinna by passing them through the cartilage defect in the pinna and simultaneously applying backward traction on the pinna ( - Fig. 2c). The auricular wing was repositioned to sit on the anterior portion of the defect (toward the concha) and was approximated with the defect anterior margin. The mastoid wing was approximated with the posterior margin of the defect (toward the helix). The central shaft of subcutaneous tissue remained attached at the auriculomastoid groove, while its skin margins were approximated to the central part of the caudal and cranial

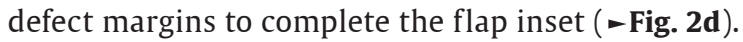

\section{Donor Site Closure}

Following flap inset, the donor site is closed primarily by approximation of the auricular and mastoid margins of flap donor defect. This also allows for coverage of the retroauricular subcutaneous pedicle (-Figs. 1c and 3f).

For assessment of ease of the flap surgery among the junior authors, the surgery was divided into flap harvest, transfer, inset, and donor site closure. Understanding and execution of each step was assessed and graded subjectively as easy, moderately difficult, or difficult. Total operative time was noted.

\section{Follow-Up}

Patients were discharged on the same day with oral antibiotics and analgesics. They were reviewed on postoperative day 1, 5, and 7. Stitches were removed on day 7 . Patients were assessed periodically for local recurrence and outcome.

Patients were observed for complications like flap congestion, pain, scaring, pinning of the ear among others. Major pinning was noted when ear projection (helical rim to scalp distance) at the upper part of auricle was $>5 \mathrm{~mm}$ and at mid part $>1 \mathrm{~cm}$. Outcomes were assessed at 6 months and 1 year and recorded.

Also, ear height to breadth ratio, three-dimensional shape and architecture, symmetry, sensation, color and texture match were assessed.

\section{Data Analysis}

All the data were tabulated and analyzed with GraphPad Prism version 8.0.0 software.

\section{Results and Analysis}

The age of the patients ranged from 32 to 70 years. Eight cases were basal cell carcinoma (BCC) and one case was pigmented nevus. The mean dimension of the flap was $27.22 \mathrm{~mm} \times 22.78 \mathrm{~mm}$. The largest flap harvested was $40 \mathrm{~mm} \times 35 \mathrm{~mm}$. The mean operative time was 56.56 minutes (standard deviation 22.50, standard error of the mean 7.5 ; - Table 1 )

The donor site was closed primarily in all cases. No recurrences were noted after a minimum period of 1 year or until patients were in follow-up. Flap congestion was noted in three cases postoperatively which resolved completely without any intervention by the second week in all cases. No flap was lost completely or partially. Major pinning of the ear was noted in four cases. It was seen mainly when larger flaps were used. In three cases pinning improved symptomatically and residual minor pinning persisted at 1-year follow-up. In one case major pinning persisted at 1-year follow-up. Minor pinning was noted in five cases and improvement was noted in four cases. Donor site scar-related complications were not seen (-Table 1).

\section{Case Reports}

\section{Case 2}

A 56-year-male presented with pigmented nevus over the scapha. After excision of the lesion, the cartilage was exposed, and defect size was $15 \mathrm{~mm} \times 20 \mathrm{~mm}$. Following reconstruction with the RD flap, no congestion of flap was noted postoperatively. Normal contour of the scapha, concavity of ear, and projection at the upper part were well maintained (-Fig. 4). Minor pinning was noted which improved with massage and no residual pinning was noted at 1-year follow-up.

\section{Case 7}

A 60-year female presented with BCC involving the conchal bowel. A $30 \mathrm{~mm} \times 30 \mathrm{~mm}$ RD flap coverage was done to resurface the defect. Initial flap congestion was noted. However, the congestion gradually subsided without any intervention by 2 weeks. Major pinning was noted which was treated with massage and use of spectacles. Minor residual pinning persisted after 1 year, but patient had no discomfort in using her spectacles. There was a diminished length/breadth ratio, but three-dimensional shape, contour, architecture, sensation, and color match were excellent (-Fig. 5).

\section{Case 8}

A 56-year-male presented with pigmented $\mathrm{BCC}$ affecting the concha. Coverage with an RD flap, $30 \mathrm{~mm} \times 25 \mathrm{~mm}$, was performed. No congestion was noted. Persistent major pinning was noted at 1 year but length/breadth ratio, three-dimensional shape, architecture, sensation, color match, and symmetry were excellent (-Fig. 6). 

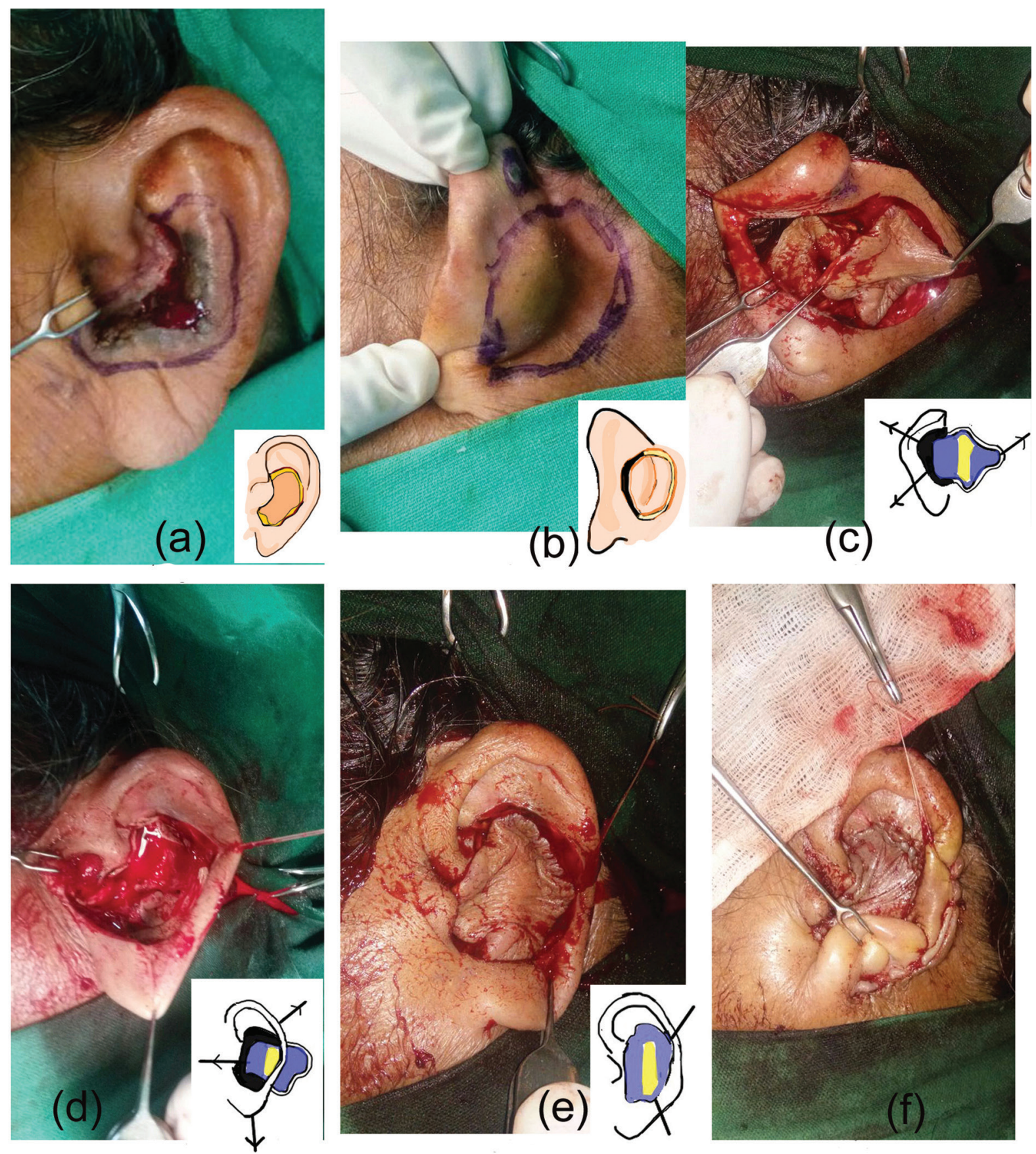

Fig. 3 Stepwise demonstration of RD flap. (a) Lesion is excised with 5-mm clear margin. The resultant loss results in anterior skin and cartilage defect as shown in inset (b) The flap is marked on the postauricular surface. (c) Flap elevation. Undermined part of the flap (retroauricular and mastoid wings) and defect are marked with blue and black ink, respectively. Flap is fixed at the retroauricular groove by its subcutaneous pedicle (marked in yellow). (d) Flap is transferred by revolving the flap through the cartilage defect or cartilage slit and simultaneous backward pull on pinna. (e) Flap inset. The anterior margin of the flap is sutured to the anterior margin of the defect. Flap remains attached at retroauricular groove via the subcutaneous pedicle as marked in yellow. (f) Closure of the flap donor site by suturing the margins primarily. RD, revolving door.

\section{Discussion}

The RD or subcutaneous pedicle (island) postauricular flap is chiefly designed to address conchal defects. The flap harvest technique is unique and can be difficult to grasp. The flap finds mention in the literature variously as the flip-flop flap, RD flap, trap door flap, postauricular island flap, retroauricular flap, subcutaneous island pedicle graft, transcartilage island pedicle flap, or pull-through flap by earlier authors. ${ }^{4-6,10,11}$
The RD flap has been classically indicated for conchal bowl defects involving the anterior surface. Flap transfer in these cases produces minimum "pinning" effect. However, its modification and extended utility for scapha, helix and antihelix, external auditory meatus, ${ }^{3,11}$ and larger auricular defect has been described earlier by Talmi, ${ }^{7}$ Rodendo, and Jackson. ${ }^{12-15}$ Although, primary closure, secondary healing, skin grafting, and other local flaps are options for resurfacing an anterior auricular defect, they are suboptimal for covering exposed 
Table 1 Operative details and complications

\begin{tabular}{|c|c|c|c|c|c|c|c|c|}
\hline Patient no. & Age/Sex & Location & $\begin{array}{l}\text { Performed } \\
\text { by }\end{array}$ & $\begin{array}{l}\text { Flap } \\
\text { dimension }\end{array}$ & $\begin{array}{l}\text { Flap } \\
\text { surgery } \\
\text { time (min) }\end{array}$ & $\begin{array}{l}\text { Operative } \\
\text { convenience }\end{array}$ & $\begin{array}{l}\text { Early } \\
\text { complications }\end{array}$ & $\begin{array}{l}\text { Pinning of } \\
\text { ear (status on } \\
\text { follow-up) }\end{array}$ \\
\hline 1 & $65 / F$ & $\begin{array}{l}\text { Conchal } \\
\text { bowl }\end{array}$ & SA & $\begin{array}{l}35 \mathrm{~mm} \times \\
20 \mathrm{~mm}\end{array}$ & 30 & - & & $\begin{array}{l}\text { Minor } \\
\text { (resolved) }\end{array}$ \\
\hline 2 & $56 / \mathrm{M}$ & Scapha & JA 1 & $\begin{array}{l}15 \mathrm{~mm} \times \\
20 \mathrm{~mm}\end{array}$ & 90 & $\begin{array}{l}\text { Moderately } \\
\text { difficult }\end{array}$ & & $\begin{array}{l}\text { Major } \\
\text { (residual } \\
\text { minor) }\end{array}$ \\
\hline 3 & $55 / F$ & $\begin{array}{l}\text { Concha and } \\
\text { helical root }\end{array}$ & JA 2 & $\begin{array}{l}35 \mathrm{~mm} \times \\
30 \mathrm{~mm}\end{array}$ & 80 & $\begin{array}{l}\text { Moderately } \\
\text { difficult }\end{array}$ & $\begin{array}{l}\text { Flap } \\
\text { congestion }\end{array}$ & $\begin{array}{l}\text { Major } \\
\text { (residual } \\
\text { minor) }\end{array}$ \\
\hline 4 & $58 / \mathrm{M}$ & $\begin{array}{l}\text { Conchal } \\
\text { bowl }\end{array}$ & SA & $\begin{array}{l}20 \mathrm{~mm} \times \\
20 \mathrm{~mm}\end{array}$ & 35 & - & & $\begin{array}{l}\text { Minor } \\
\text { (resolved) }\end{array}$ \\
\hline 5 & $60 / M$ & Scapha & JA 1 & $\begin{array}{l}20 \mathrm{~mm} \times \\
20 \mathrm{~mm}\end{array}$ & 70 & Easy & & $\begin{array}{l}\text { Minor } \\
\text { (resolved) }\end{array}$ \\
\hline 6 & $52 / \mathrm{M}$ & $\begin{array}{l}\text { Conchal } \\
\text { bowl and } \\
\text { root of helix }\end{array}$ & JA 2 & $\begin{array}{l}40 \mathrm{~mm} \times \\
20 \mathrm{~mm}\end{array}$ & 70 & Easy & $\begin{array}{l}\text { Flap } \\
\text { congestion }\end{array}$ & $\begin{array}{l}\text { Minor } \\
\text { (persisting) }\end{array}$ \\
\hline 7 & $68 / F$ & $\begin{array}{l}\text { Conchal } \\
\text { bowl }\end{array}$ & SA & $\begin{array}{l}30 \mathrm{~mm} \times \\
30 \mathrm{~mm}\end{array}$ & 30 & - & $\begin{array}{l}\text { Flap } \\
\text { congestion }\end{array}$ & $\begin{array}{l}\text { Major } \\
\text { (residual } \\
\text { minor) }\end{array}$ \\
\hline 8 & $56 / \mathrm{M}$ & $\begin{array}{l}\text { Conchal } \\
\text { bowl }\end{array}$ & JA 1 & $\begin{array}{l}30 \mathrm{~mm} \times \\
25 \mathrm{~mm}\end{array}$ & 60 & $\begin{array}{l}\text { Moderately } \\
\text { difficult }\end{array}$ & & $\begin{array}{l}\text { Major } \\
\text { (residual } \\
\text { major) }\end{array}$ \\
\hline 9 & $55 / \mathrm{M}$ & $\begin{array}{l}\text { Conchal } \\
\text { bowl }\end{array}$ & JA 2 & $\begin{array}{l}20 \mathrm{~mm} \times \\
20 \mathrm{~mm}\end{array}$ & 45 & Easy & & $\begin{array}{l}\text { Minor } \\
\text { (resolved) }\end{array}$ \\
\hline
\end{tabular}

Abbreviations: F, female; JA, junior author; M, male; SA, senior author.

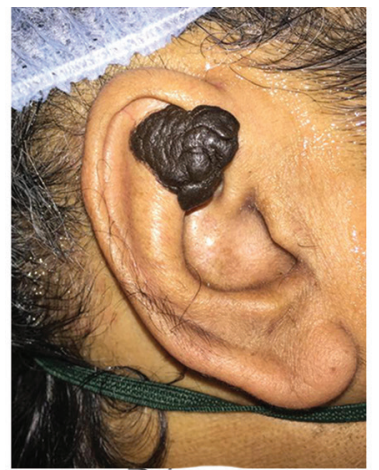

(a)

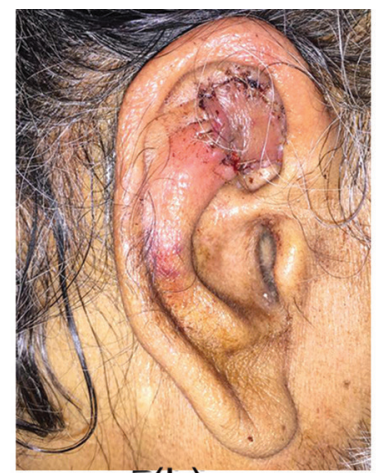

(b)
Fig. 4 Revolving door flap for scapha defect. (a) Preoperative and (b) immediate postoperative photograph.

cartilage or composite defects involving anterior skin and cartilage. ${ }^{5,6,16}$ The RD flap provides a pliable cover to bare cartilage and helps resurface complex auricular defects maintaining its three-dimensional form and morphology along with primary closure of donor site and a well-hidden scar. Moreover, it has the advantage of being a single stage procedure that can be performed under local anesthesia with a short operative time. ${ }^{6,8,16,17}$ Furthermore, the neurovascular pedicle allows for preservation of sensation as noted by Nguyen and Bordeaux, ${ }^{5}$ Turan et $a{ }^{8}{ }^{8}$ and by us.

The RD flap is supplied by the auricular branch of postauricular artery in the retroauricular groove. The subcutaneous pedicle allows a wide range of movement to the flap due to its rich vascularity. Up to $6 \mathrm{~cm} \times 6 \mathrm{~cm}$ flap may be elevated. ${ }^{18}$ The donor defect can be closed primarily in most of the cases. The major drawbacks of the RD flap are "pinning" of auricle to scalp and venous congestion. Pinning is of particular concern for larger flaps and a more peripheral auricular flap harvest but may improve with intralesional triamcinolone or physiotherapy over time. In our series, major pinning was seen in four out of nine cases, of which three had flap dimensions of $3 \mathrm{~cm}$ or more. In all but one case, major pinning resolved on conservative therapy at 1-year follow-up (-Table 1). The use of undermining or local flaps from the surrounding tissue to minimize it and Z-plasty as corrective measures for it also has been described. ${ }^{10,11}$ There is a chance of flap congestion if the flap is either too small ${ }^{6}$ or too large, nonetheless incidence of total or partial flap loss is extremely rare.

The RD flap yields predictable results though it is uncommonly performed. ${ }^{1}$ Talmi et al ${ }^{19}$ reported 21 cases (1997-2002) and Schonauer et al $^{9}$ performed 57 flaps in 5 years (2002-2007). Papadopoulos et al $^{6}$ found poor results in only one case among 62 patients over 10 years (2008). Dessy et al $^{1}$ showed a better outcome than FTSG in 20 cases in a 4-year study (2003-2007). Iljin et $\mathrm{al}^{13}$ had found good outcomes in 13 cases over 13 years (2000-2013). No flap loss was reported with standard flap design in these series. Good cosmetic results were described by all. Pinning of ear to scalp was reported as the most common concern of the surgical outcome.

In our case series, the critical step was to preserve a sufficient subcutaneous pedicle in the auriculomastoid groove at the 


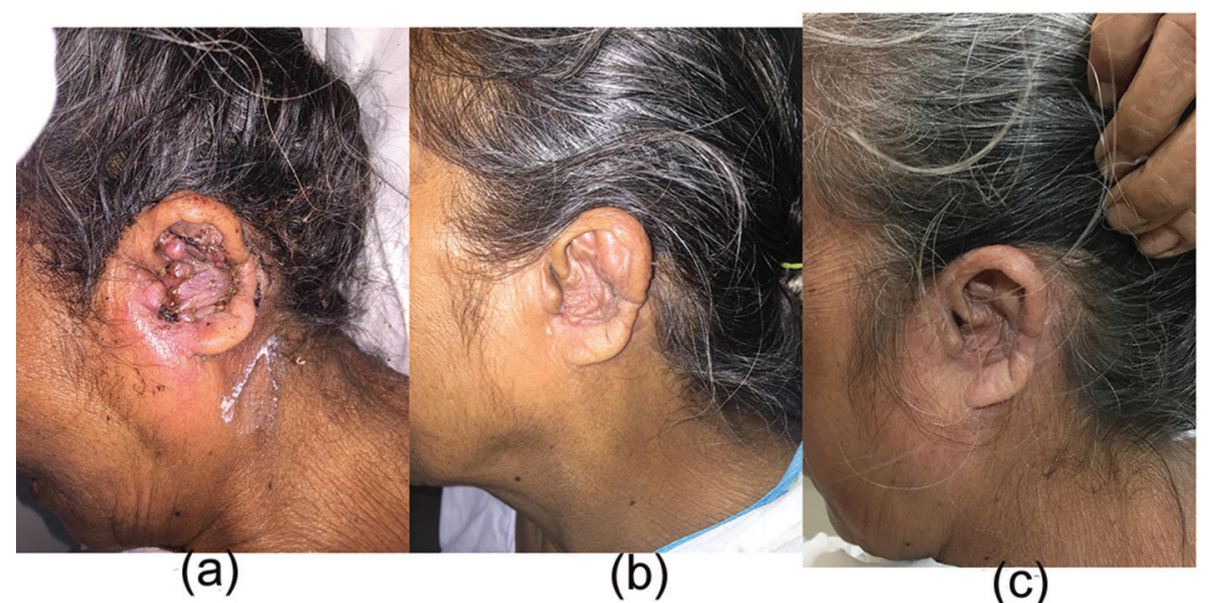

Fig. 5 Revolving door flap for conchal bowl defect. Initial flap congestion was noted in the postoperative period (a). However, congestion improved without any flap loss. Improved outcome noted at 6-month (b) and at 1-year follow-up (c).

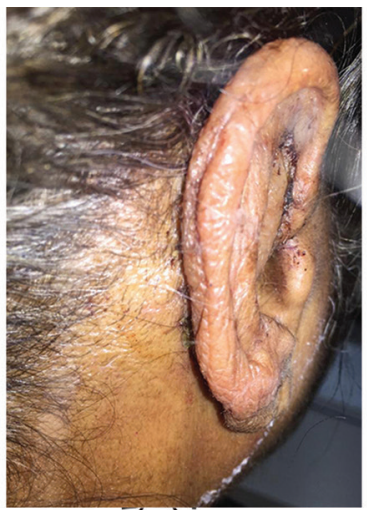

(a)

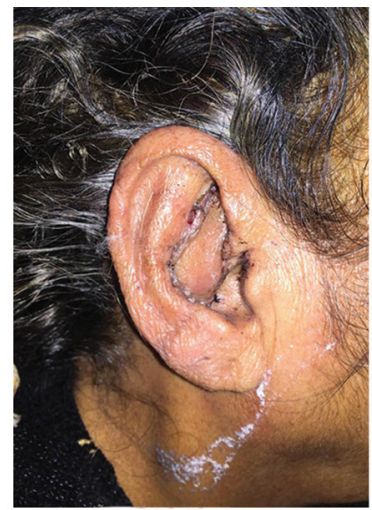

(b)
Fig. 6 Revolving door flap for conchal defect with demonstration of pinning effect. Pinning is noted (a) through contour and shape is well maintained (b).

axis of the flap. Pulling the flap forward and pinna backward helped transfer the flap through the auricular cartilage defect like a "buttonhole." In this manner the flap finally rotates like a RD on the hinge of its subcutaneous pedicle. Keeping in mind to match the anterior border of flap to anterior border of the defect helped us to simplify the design and transfer of the flap (-Figs. 1 and 2). We have noted that sparing at least a 5-mm wide subcutaneous pedicle allows adequate flap movement without compromising the vascularity. Further flap movement may be obtained, as necessary in larger flaps at the cost of pinning of the ear and flap congestion. But the necessary flap movement almost never leads to flap failure.

\section{Conclusion}

Though infrequently performed, the RD flap has an easy learning curve once the proper harvest technique and flap movement has been grasped. The RD flap harvest is convenient, safe, and yields predictable results even in the hands of a novice. Not only is total or partial flap loss extremely rare, the flap is sensate, color match is good, auricular contour is maintained, and the donor site can be closed primarily and remains well hidden. Although pinning of the ear is a major concern and is seen frequently, it improves over time. The understanding of flap design and transfer is essential for this unique and elegant flap.

\section{Limitations}

This is a single institute study trying to assess the utility and learning curve of the RD flap subjectively. Objective assessment was beyond the scope of the present study due to small number of cases. Increasing the number of cases by involving multiple institutions or other practitioners could have addressed the issue with more certainty.

\section{Funding}

None.

\section{Conflict of Interest}

None declared.

\section{References}

1 Dessy LA, Figus A, Fioramonti P, Mazzocchi M, Scuderi N. Reconstruction of anterior auricular conchal defect after malignancy excision: revolving-door flap versus full-thickness skin graft. J Plast Reconstr Aesthet Surg 2010;63(5):746-752

2 Masson JK. A simple island flap for reconstruction of concha-helix defects. Br J Plast Surg 1972;25(4):399-403

3 Jackson IT, Milligan L, Agrawal K. Versatile revolving door flap in the reconstruction of ear defects. Eur J Plast Surg 1994;17(3):131-133

4 Lynch J, Mahajan AL, Regan P. The trap door flap for reconstructing defects of the concha. Br J Plast Surg 2003;56(7):709-711

5 Nguyen DH, Bordeaux JS. Pull-through subcutaneous pedicle flap for an anterior auricular defect. Dermatol Surg 2010;36(6):945-949

6 Papadopoulos ON, Karypidis DK, Chrisostomidis CI, Konofaos $\mathrm{PP}$, Frangoulis MB. One-stage reconstruction of the antihelix and concha using postauricular island flap. Clin Exp Dermatol 2008;33(5):647-650 
7 Talmi YP, Liokumovitch P, Wolf M, Horowitz Z, Kopolovitch $\mathrm{J}$, Kronenberg J. Anatomy of the postauricular island "revolving door" flap ("flip-flop" flap). Ann Plast Surg 1997;39(6):603-607

8 Turan A, Turkaslan T, Kul Z, Isler C, Ozsoy Z. Reconstruction of the anterior surface of the ear using a postauricular pullthrough neurovascular island flap. Ann Plast Surg 2006;56(6): 609-613

9 Schonauer F, Vuppalapati G, Marlino S, Santorelli A, Canta L, Molea G. Versatility of the posterior auricular flap in partial ear reconstruction. Plast Reconstr Surg 2010;126(4):1213-1221

10 Fader DJ, Johnson TM. Ear reconstruction utilizing the subcutaneous island pedicle graft (flip-flop) flap. Dermatol Surg 1999;25(2):94-96

11 Wang SQ Goldberg LH, Asadi AK. Surgical conundrum: transcartilage island pedicle flap for a scapha defect. Dermatol Surg 2009;35(3):505-508

12 Humphreys TR, Goldberg LH, Wiemer DR. The postauricular (revolving door) island pedicle flap revisited. Dermatol Surg 1996;22(2):148-150

13 Iljin A, Lewandowicz E, Antoszewski B, Durko M, Zieliński T. Results of auricular Conchal bowl reconstructions following cancer resections with postauricular island flap. Pol Przegl Chir 2016;88(6):315-320
14 Nemir S, Hunter-Ellul L, Codrea V, Wagner R. Reconstruction of a large anterior defect after Mohs micrographic surgery with a cartilage graft and postauricular revolving door flap. Case Rep Dermatol Med 2015;2015:484819

15 Politi M, Robiony M. Anthelix-conchal reconstruction with postauricular "revolving door" island flap. Int J Oral Maxillofac Surg 1995;24(5):340-341

16 Ruiz M, Garcia O, Hernán I, Sancho J, Serracanta J, Barret JP. Revolving-door flap: an alternative for the coverage of acute burn defects of the auricle. Burns 2011;37(6):e41-e43

17 Oh MJ, Kang SJ, Sun H. A simple modified flip-flop flap for the reconstruction of antihelix and triangular fossa defects. Arch Plast Surg 2016;43(1):122-124

18 Talmi YP, Horowitz Z, Bedrin L, Kronenberg J. Technique of auricular reconstruction with a postauricular island flap 'flip-flop flap'. Oper Tech Otolaryngol-Head Neck Surg 2000;11(4):313-317

19 Talmi YP, Wolf M, Horowitz Z, Bedrin L, Kronenberg J. "Second look" at auricular reconstruction with a postauricular island flap: “flip-flop flap". Plast Reconstr Surg 2002;109(2):713-715 